\title{
Stand by Me
}

\author{
Santosh K. Chaturvedi
}

Received: 27 October 2019/Accepted: 28 October 2019/Published online: 4 November 2019

(C) Springer Nature India Private Limited 2019

Support from family, friends and society has an important role in recovery from any situation related to disease, disability or death. Certain events can take a heavy toll on the individual's life and coping alone can be difficult. People are getting more and more isolated and life is getting centred on individual living, bearing and coping. Nevertheless, society has devised traditions and customs to ensure that such support is available to every one at times of their difficulties. I witnessed one such 'stand by me' moment of solidarity recently, after the untimely death of my dear elder brother. As a part of the death rituals, there is a long walk from the cremation ground to the banks of the holy river of Yamuna at my home town Mathura. The walk with close family members can be extremely lonely, but fortunately, we were joined by many more, distant and near relatives, friends, neighbours and well-wishers, which gave us a feeling of not being alone, and there were so many more, not so familiar faces, who stood by us. It is a unique March, as we led the walk till the ghat [bank of river], and stood there, and the procession passed us, only to queue up, and let us proceed towards home, an exemplary example of standing by each other. Even more memorable is the fact that in the beginning of the walk, we were only a

S. K. Chaturvedi $(\bowtie)$

Psychiatric Rehabilitation Services, National Institute of Mental Health and Neurosciences, Bangalore, India

e-mail: skchatur@gmail.com handful, led by my nephew and me, and by the time we reached the end of the journey, many had joined from different places along the route. In moments of immense weakness due to the bereavement, this societal strength was a great solace. It reminded me of a classic song by Ben E King who asks "Whenever you're in trouble, won't you stand by me? Oh, stand by me".

Similar must be the strength from family and society felt by persons faced with other chronic or acute diseases and disabilities. This invisible support raises to the occasions when needed most. Hence, in most rehabilitation and supportive plans, garnering social support emerges as an important aspect, besides vocational issues.

\section{Social Media, the New Social Support}

Much as one can appreciate the value of support from live persons, the role of social media in providing support cannot be ignored. Use of technology, internet and social media is at the receiving end of critics and cynics. With growing use of technology and internet, professionals and public are panicking about its adverse effects, on others, more than on themselves! Though one must be cautious about any ill effects on health and mental health, the benefits of technology and internet in healthcare should also be acknowledged. Certain social media, specially, Facebook, 
Instagram, and WhatsApp, have the power to revive connections between family and friends. In my personal story written above, social networks got active in minutes and hours, word spread around about our loss, far and wide, which would definitely not have been possible without internet. Two Facebook mentions got hundreds of our family, friends and wellwishers sending condolences and support. Hopefully, health and mental health professionals would use technology and its accessories to an advantage for promotive, preventive, curative and rehabilitative aspects of healthcare.

In this context, the current issue of the journal, has a few papers focusing on support, including from emotional support animals. There are informative articles on the perspectives of survivors and caregivers of persons with traumatic brain injury, treatment of mentally ill offenders, and caregiver burden of persons with schizophrenia. This issue is also unique in having an article on decision making process in mental health care, and hospital-based income generation activities for persons with mental health challenges in a psychiatric rehabilitation facility. The issue also has a qualitative account of patients' lived experiences of hospitalization for a mental health disorder.

Further, there are contributors from Sweden, Norway, Switzerland, Ghana and Indonesia, besides those from Canada, United States of America, and India. The journal has completed its sixth year of publishing and this international coverage of contributors and of course readers is very encouraging. Of course, use of technology in submissions, review and publishing have only made this easier.

Santosh K Chaturvedi Editor in Chief 